\title{
ACHIEVING HIGH COMMITMENT IN AND OF SOURCING DECISIONS - A DECISION-MAKING PARADOX
}

\author{
Björn Johansson \\ Department of Informatics, Jönköping International Business School, Jönköping University
}

\begin{abstract}
This paper describes a sourcing decision process and how that process is done in order to achieve high commitment in and of sourcing decisions. It can be stated that it is important with high commitment in and of sourcing decisions for the process as well as the result to be successful. The study uses a decision-making process in a Swedish municipality to describe the importance of having high commitment and how high commitment can be achieved. The sourcing decision process was a decision-making process where the final result was an internal reorganisation in the municipality regarding hosting of software applications. From an outsourcing point of view this can be described as internal outsourcing. The structure of the hosting was before the decision highly decentralised. The objective and the goal of the decision were to centralise hosting of software applications. There was weak motivation for changing the structure and thereby low commitment among involved stakeholders at the start of the process. The case shows how the decision-makers conducted the decision-making process in order to increase commitment of the already taken decision. That the decision already was taken at the start of the process indicates that the decision could be described as a decision-making paradox. From the case it can be concluded that the decision-making process was successful and that the high commitment existing after the process indicates that the outcome of the decision will have high potential to be successful as well.
\end{abstract}

\section{Introduction}

The success of sourcing decisions and especially outsourcing decisions to a high extent depends on stakeholders' commitment. The question is how decision-makers and the decision-making process can influence or impact the commitment. It is also a question of what it is that influences the commitment. That it is important to have commitment is probably a consensus about. However, how to achieve commitment is probably not that clear. The question could be what kind of decision-making process that is the best in the specific situation. This study uses a sourcing decision process in a Swedish municipality to show one way how decision-makers try to increase commitment. The organisation of the municipality is to a high extent influenced by thoughts about decentralisation. This has resulted in a highly decentralised structure of the ICT function, and that the different offices in the municipality have their own organisation for the hosting of software applications. This structure is described as a problem for the municipality when they aim at becoming an e-government. The reorganisation of the hosting was described as something nescessary to do. However, this is very much against the ideology of the municipality, which indicates that there is low commitment at hand. The questions discussed in the paper are: 1) is it possible to increase commitment in and of sourcing decisions, and, if so, 2) how can that be done?

The paper is organised in the following way. Section 2 describes decision-making in organisations and how this is affected by the desire to have high commitment. Section 3 describes sourcing decisions and especially why high commitment is necessary to have as well as why it is hard to have high commitment in and of a sourcing decision. Section 4 describes the retrospective study of the municipality that works as empirical evidence of the findings. Section five discusses how the sourcing decision was made in the municipality and how the decision-making process influences the commitment of the final decision taken. The final section summarises the discussion and gives some conclusions that can be drawn from the study.

\section{Achieving High Commitment in Decision- Making}

In order to describe decision-making and commitment, Simon's (1976) discussion about decisionmaking in organisations is used as a starting point. He states that an important distinction in decision-making is that managers operate under pressure of bounded rationality, and decision-makers intend to show that they make rational decisions. This distinction can be compared with the concept labelled distortion 
(Salaman, 2002). Distortion, according to Salaman, means that you have to understand that you sometimes get the wrong description of how a decision was made when you ask somebody about the process of that decision. When you ask the person or people who acted as decision-makers, you should be aware that they often modify the description of the decision process. This implies that the decision is probably described as more rational than it actually was. My conclusion from this is that the decision-makers' behaviour is not completely rational, nor is it irrational (Miller et al., 2002). According to Miller et al., Simon says that decisions can be processed in different ways and as such can be categorised into two overall kinds of decisions, programmed and non-programmed. These two differ in how frequent, familiar and routine the decisions are, but also if there is a procedure worked out for handling the decision. Programmed decisions are often made in a more straightforward fashion that can be executed in a rational, logical and linear step-by-step approach. The non-programmed decisions are instead novel and unusual and therefore challenge the decision-maker. In addition, the nonprogrammed decision is often more strategic for the organisation.

However, Gorry and Scott Morton (1989) use the term structured and unstructured for programmed and non-programmed decisions. Linking this to a statement made by Jurison (1995) would imply that the decision of using a specific sourcing option is a programmed decision. This statement can be questioned, and there is a need to look deeper into how the process of choosing a specific sourcing solution is constructed. In my view sourcing decisions are more related to what Gorry and Scott Morton describe as strategic planning. Strategic planning is defined as "the process of deciding on objectives of the organisation, on changes in these objectives, on the resources used to attain these objectives, and on the policies that are to govern the acquisition, use, and disposition of these resources" (Gorry \& Scott Morton, 1989, p. 50). In my view strategic planning is certainly a decisionmaking process that can be described as both nonprogrammed as well as unstructured. I would say that sourcing decisions are important and impact organisations to a high extent, since they aim at organisational change or action.

When discussing decision-making processes and specifically when looking at decision-making with the aim of organisational change, there are, to Brunsson (1985), three concepts that are important to discuss: motivation, expectation and commitment. Each of these plays an important role in the decision-making and can be described as a condition within both the organisation as well as within decision-makers. In addition to these concepts also uncertainty and risk impact or influence decision-making in decisions aiming at organisational change. One interpretation of how Brunsson describes the relation between these five concepts or rationalities in decision-making is shown in Figure 1.

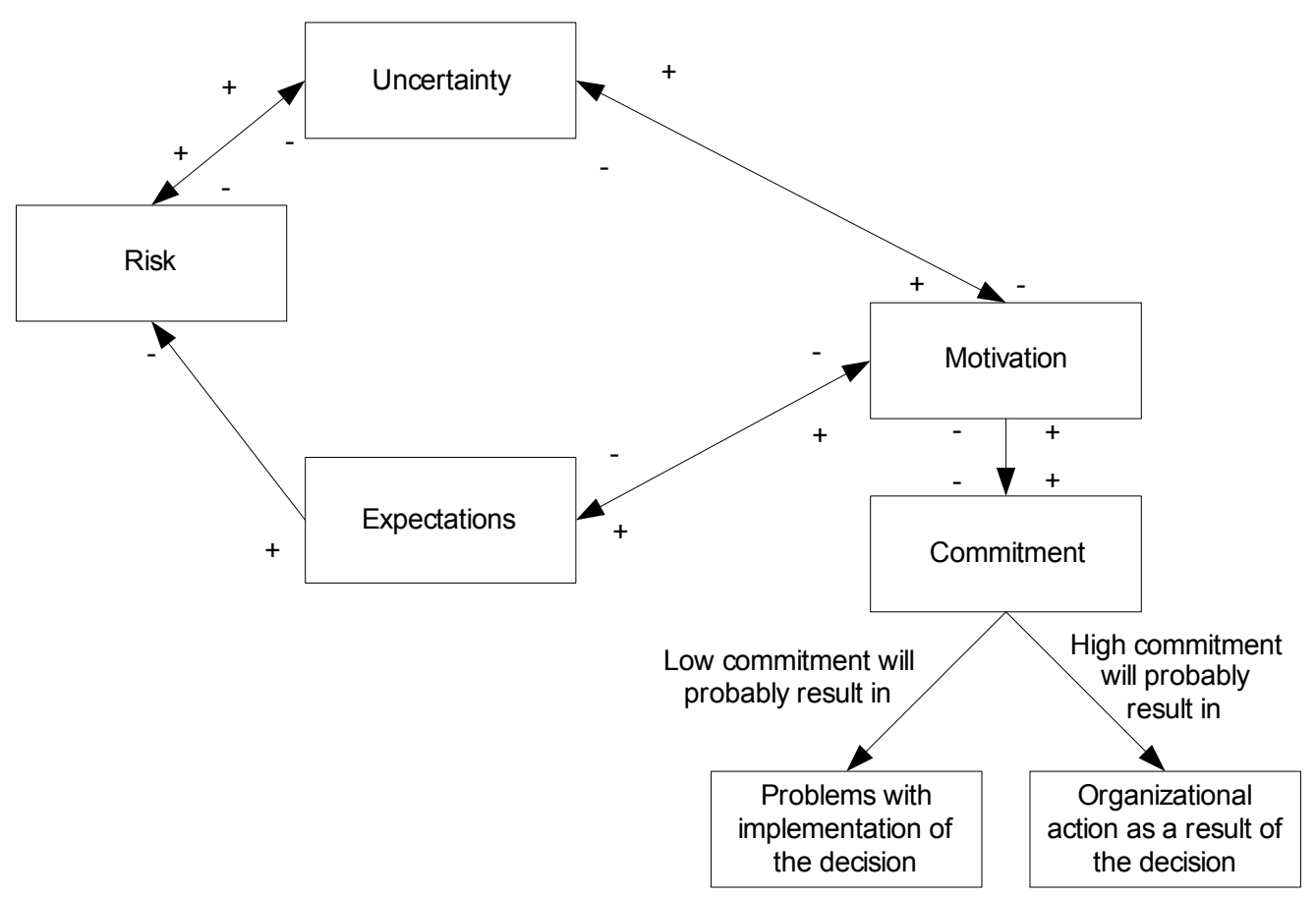

Figure 1. Relations between rationalities in decision-making

To Brunsson, uncertainty is a concept that is widely discussed in organisation theory. To him, there are numerous definitions of the concept. Hatch (1997) states that uncertainty earlier was considered to be a result of complexity and rate of change and as such seen as a property of the environment. The problem with that definition was that it was found that conditions in the environment were not experienced in the 
same way by everyone. The statement Hatch makes is that this definition was misleading since environments do not feel uncertain. Instead, the people in the environment are the ones who feel uncertain. From that it can be stated that it is not the environmental conditions that make decision-makers uncertain; instead, it is the decision-maker's perception of the environment that can result in uncertainty. This means that if the environment is seen as unpredictable decision-makers feel uncertain. According to Hatch, there are four different modes of certainty/uncertainty, as shown in Table 1.

Table 1. Links between conditions in the perceived environment, uncertainty, and information (Hatch, p.91, 1997)

\begin{tabular}{|c|c|c|}
\hline Rate of change/ complexity & Low & High \\
\hline Low & $\begin{array}{c}\text { Needed information is known and } \\
\text { available }\end{array}$ & Constant need for new information \\
\hline High & Information overload & $\begin{array}{c}\text { Not known what information is } \\
\text { needed }\end{array}$ \\
\hline
\end{tabular}

These modes, as described in Table 1, depend on the amount of information available for decisionmakers as well as if the decision-makers know what information they need. One view of this is that it is only in one mode that decision-makers feel certain and that is when needed information is known and available. However, it can be stated that this occasion is rare and to a high extent depend on the behaviour of the decision-maker. For instance, if two different decision-makers have the same information they would probably perceive that information differently. It could be that one says this is enough, while the other says I need more or this is too much or I want more but I do not know what information I need.

According to Brunsson (1985) there are difficulties in defining uncertainty, and he relates the definitions of uncertainty to broadly two different stands. The first sees uncertainty as something outside the decision-makers describing the world outside. This means that uncertainty can be defined as lack of information. The other stands describe uncertainty as a state of mind of individuals. The latter point of view is the one that Brunsson adopts. Brunsson describes uncertainty as a lack of confidence or belief in the decision-makers' cognitive structure of a situation. This means that uncertainty is lack of confidence in the information at hand and not lack of information (Brunsson, 1985, p. 38).

However, it is clearly stated that uncertainty impacts and influences decision-making to a great extent. According to Brunsson uncertainty does influence motivation. Motivation is seen as the basic input to expectations. Figure 1 should be interpreted in the following way: an increase in motivation increases expectations, an increase in expectations means an increase in motivation and a decrease of perceived risks. The discussion about uncertainty reveals that uncertainty can exist in three different settings: uncertainty in cognitive structures, uncertainty about judgments and uncertainty about estimations (Brunsson, 1985). Uncertainty in cognitive structures means that decision-makers are unsure if the picture of the situation represents a valid picture of the reality. Judgments uncertainty means that the decision-maker experiences uncertainty about the decision related to the normative area of the decision-maker's cognitive structure. The decision-makers are therefore unsure about wanted values, and if these values are good or bad. Uncertainty about estimations is when decisionmakers become unsure about if estimation of a given value is correct. All these different kinds of uncertainties have an impact on the level of motivation which results in an impact on decision-makers' expectations. This means that motivation and expectation to a great extent influence the outcomes of the decisions. However, there is, according to Brunsson, another concept that needs to be discussed when discussing outcomes of decision-making and that is risk. The level of risk heavily influences the decision-makers to decide in different directions. Risk is defined by Brunsson as the product of uncertainty multiplied with stakes. In Figure 1 it is shown that an increase in perceived risks increases uncertainty and therefore a decrease in motivations takes place. However, a decrease as well as an increase of perceived risks will probably not directly affect the level of expectations.

When it comes to decision-making aimed at organisational change, Brunsson describes two methods or modes of how to propose changes in an organisation. He labels these rationalistic and impressionistic. The difference between these methods is how the decision-making starts. The rationalistic method starts from estimating value of the outcome of the decision, and from that develop how to receive organisational action. The impressionistic method starts from the other direction by using the known values of the factors. Brunsson claims that the impressionistic method is much better at receiving organisational action. The reason for this is that it decreases risks by decreasing uncertainty. The rationalistic method decreases risk but it does so by decreasing stakes and not the uncertainty. This means that it decreases the motivation for making any changes as a result from the decision-making process. This can be compared with the statements made by Udo (2000). He concludes that his study shows that it is possible to use a systematic approach for decisions that are conducted under a high level of uncertainty. He says that by using a systematic approach the level of uncertainty is 
reduced. However, if using Brunsson's definition of uncertainty, presenting more options does not decrease uncertainty, instead it increases uncertainty. It can be argued that whether uncertainty increases or not, when more options to choose between are presented, depends on what the decision is about. But, in most cases and especially in the case of a sourcing decision increasing the number of possible options increases the uncertainty.

Another stand that impacts decision-making according to Brunsson is ideologies. Ideologies and especial organisational ideologies are described by Brunsson as deciding on the ability for organisations to act. The ideologies influence decision-making both directly as well as indirectly. According to Brunsson, there are three aspects of ideologies that affect decision-making: conclusiveness, consistency and complexity. He claims that the more conclusive, consistent and complex the ideology is, expressed as a strong ideology, the more adaptive to environmental change is the organisation. The opposite is present in the organisation with an inclusive, inconsistent and simple ideology. That kind of organisation is not so triggered by the environment in its change. Brunsson labels this a changeable organisation while the other is labelled a changeful organisation. These two organisations differ in how they are controlled, and according to Brunsson this difference is particularly important in political organisations. However, before describing the political organisation and its sourcing decision process the next section will describe sourcing decisions and the need to have commitment in and of such decisions.

\section{Sourcing Decisions and Commitment}

Initially, it was stated that sourcing decisions need to have high commitment to be successful. This implies at least two questions: For the first what is a successful sourcing decision, and second what are the reasons that make specifically sourcing decisions to have a high need for commitment?

The question about successful is hard to answer. It could be stated that it depends on the expectations that exist as a result from the decision. In that way it can be said to be closely related to the productivity paradox as described by, for instance, Brynjolfsson (1992) and Willcocks and Lester (1996) or evolution of software applications into being a commodity as described by Carr (2004) as well as by Falk (2003). However, it can be asked what the productivity paradox and software applications as commodity have to do with a sourcing decision. To describe that, it is necessary to describe what sourcing decisions are about. Sourcing decisions are about three different working tasks related to software applications: development of software applications, maintenance of software applications, and operation or hosting of software applications. Sourcing should be seen as a broad term for how an organisation provides itself with something and in this case hosting of software applications. In a broad sense it can be claimed that irrespective of what products or services organisations need, they have two distinct options, produce or purchase, or in other words, make or buy (Williamson, 1975). This means that they can arrange or produce the services or products by themselves or they can buy them. Using outsourcing as a concept to describe a sourcing decision means that a sourcing decision is a decision whether the organisation should outsource or not. Two of the most reported reasons for starting outsourcing decisions are a need to decrease costs or focusing on core business (Gorla et al., 2002; Dibbern et al., 2004).

From this it can be concluded that sourcing decisions are related to the software applications productivity gap as described by, for instance, Brynjolfsson (2003). He claims that the question is not if a software application pays off, instead it is a question of how to best use these resources in the organisation, meaning that it is a question about the impact and influence of software applications in organisations. However, it also relates to a question of why organisations start a sourcing decision-making process, perhaps resulting in that they would implement something that is new and unfamiliar to them.

It can be said that the use and thereby the role of software applications in organisations has increased during the past few years (van Grembergen et al., 2004), and especially since Internet was introduced. According to McCauley (2004) there have lately been high investments in software applications in organisations. These investments has, according to Carr (2004), resulted in that software applications in organisations have become so much used and so widely used among organisations that it has become a commodity. The concept commodity is widely used in the context of economy and business and is there described as something one can trade and the value of it comes when one sells it and not when one uses it. Electricity and oil are often described as commodities and are, when using the above definition, valuable for those who are in the position of ownership of these resources and could earn money by selling it. Carr uses the comparison to a great extent which also Junghagen (1998) as well as Falk (2003) do. Eriksen (2003) states that the comparison with electricity and oil is not doable and the reason he states for that is that software applications should be connected to its context. However, electricity and oil can be compared with software applications in one way and that is that both electricity and oil are necessary for organisations to do their business, but, as stated by Eriksen, having more of these resources than necessary does not create a higher return. From this discussion, it can be concluded that software applications are more or less necessary for most organisations today, and software applications are to a high extent intertwined in most organisations business processes. It can also be claimed that software applications have become so ordinary in organisations that the organisations take 
them for granted. This is in line with the basic assumption that Carr (2003) states when he claims that software applications have become so basic that it does not create a business advantage by itself, which means that having more software applications does not alone create business value. This is also in line with statements from Mata et al. (1995) as well as Eriksen (2003) when they state that it is not the resource in itself that makes the competitive advantage; instead, it is how the resource is used that makes if the organisation becomes competitive by using the resource. Carr (2003) claims that when technologies' value fades it is even more important to have the skill to use it on a day-to-day basis for the organisations' success. This is very much in line with the claim that Smith and Fingar (2003) make when they state that software applications do not matter but business processes do.

However, since software applications are integrated in organisations' business processes, it becomes hard to say in what way the process is influenced by software applications. An organisation can relatively easy say what software applications are used in a specific process, but it is much harder to say in what way the software impact the process. Another difficult question related to software applications and business processes is how to separate the usage of software applications from the software application itself. All this makes that sourcing decisions are something that should be of interest for the entire organisation. The reason is both the difficulties of evaluating what impact software applications have on organisations' business processes as well as difficulties with justifying the costs of software applications. It is also a question about if software applications deliver competitive advantage or not that according to Mata et al. (1995) is a question of how the resources are used. This can be compared with the report from McCauley (2004) that claims that despite that European organisations have invested as much as American organisations, the European productivity has not increased as much as the American. The conclusion McCauley (2004) makes is that this is because there are differences in the effectiveness of software applications related to the usage of software applications. The reasons for the differences are according to McCauley that there are weaknesses in the management of software applications as well as in the awareness of what technologies exist. This indicates that it is not how much investments that are made that make productivity increase; instead, it is a question of how the resources are used. However, this discussion shows that software applications are heavily intertwined in organisations and most employees work with or are affected by software applications. It also shows that software applications' benefits are questioned. This together makes that high commitment when changing how hosting of software applications is made is needed. The next section will present a case study of a sourcing decision and from that a discussion about how organisations achieve high commitment in and of sourcing decisions will be conducted.

\section{The Municipality Sourcing Decision Case}

This section reports from a retrospective case study of a decision-making process done in a Swedish municipality. In 2002 the municipality, a local government, started to investigate how they should organise its hosting of software applications. The case study of this process consists of eleven semi-structured, tape recorded, interviews. The interviews were made in January 2005, just after the decision-making process was finalised. The material under investigation also consists of documented materials in the form of minutes, but also reports from investigations made by the participants in the decision-making process employed by the municipality. It also includes an external consultancy report. A content analysis was made. The discussion presented above about commitment in decision-making as well as sourcing decisions and commitment have been used to structure the analysis and should be seen as a point of departure for the analysis.

According to Pettigrew (1973), it is important to describe and understand the history of the organisation if a decision-making process should be described in an appropriate way. The history of the municipality can be described by its ideology, which is to strive for a great extent of decentralisation. The municipality administrative unit consists of eleven different offices. Six of these offices are organised into one group, the municipal executive office. The other five are selforganised offices. They are supposed to be supervised by the municipal executive office. However, as the ideology of the municipality focuses on decentralisation to a great extent, these offices have a far-reaching decision authority. The effects of this ideology are very clearly shown in how the municipality has organised its hosting of software applications. Each of the offices has developed its own organisation of software applications and hosting of their software applications. However, the municipal executive office is meant to have the overall responsibility for the municipality's general infrastructure regarding software applications. To illustrate the effect of this decentralisation and the evolvement of software applications in the municipality, it can be mentioned that a great diversity of software are used in the municipality. There are nine different office products, eleven different database systems, sixteen different operative systems, five different e-mail software and 66 different software applications that are identified as critical for the municipality. In addition to those 66 software applications, there are an unidentified number of software applications. This could illustrate the reason for the decisionmaking process. As described by the chief executive officer (CEO) in the municipal executive office "the welter of the municipality's software applications and ICT has to be controlled". This could probably be 
seen as the starting point of the decision-making process and the project "ICT and telephony coordination".

\subsection{The sourcing decision process}

The process started, as shown in Figure 2, in March 2002. A standing committee, consisting of the five municipal commissioners and the CEO of the municipal executive office, gave the municipal executive office the task to investigate the infrastructure of common software applications in the municipality. The reason was the expansion of software applications used in the municipality. The directions were to review the municipality's general infrastructure of software applications. The investigation should define the municipal executive office's responsibilities of development, maintenance and hosting of the municipality's general software applications. It should also describe the need for competence development and how this should be arranged. After this directive the municipal executive office engaged an external consultant to make the investigation. The consultant interviewed employees in different offices, including some employees with responsibilities for the different office's software applications. The consultant stated that the organisation of software applications was distinguished, to a great extent, by decentralisation, and there were no established long-term plans for evolution of software applications.

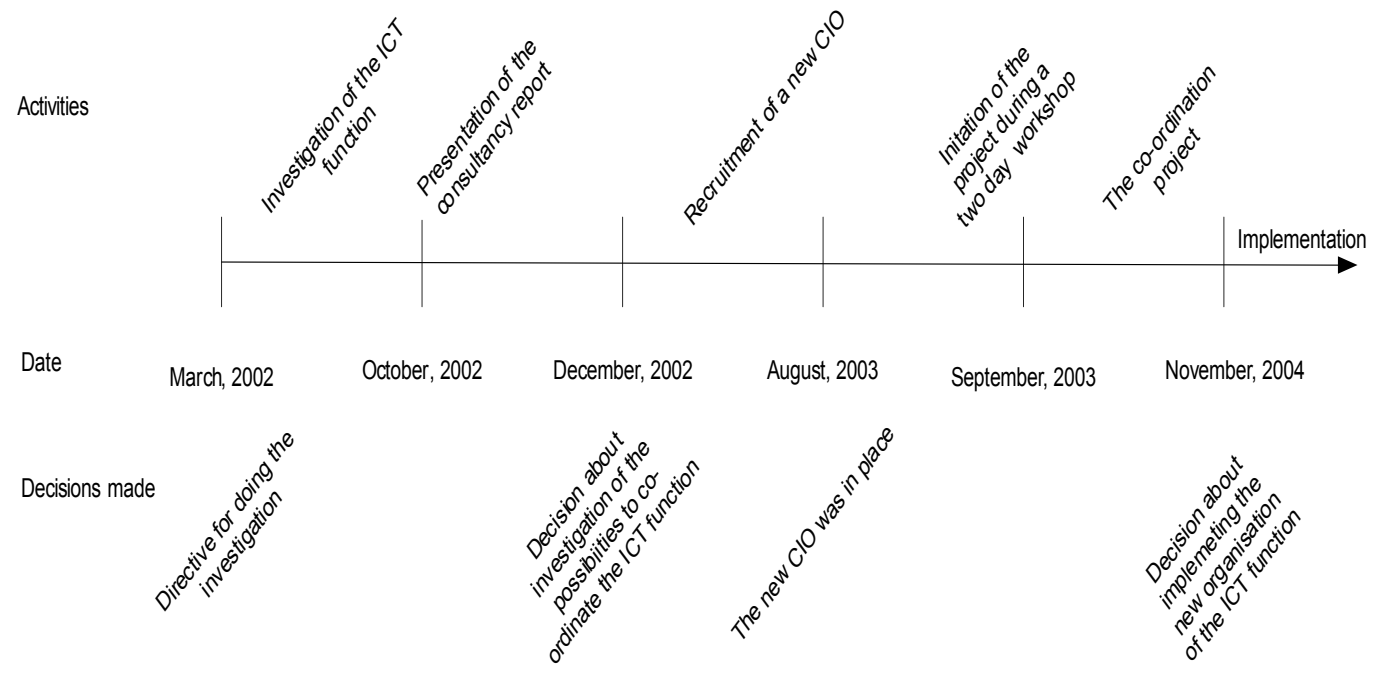

Figure 2. Timeline for the municipality's investigation and coordination project

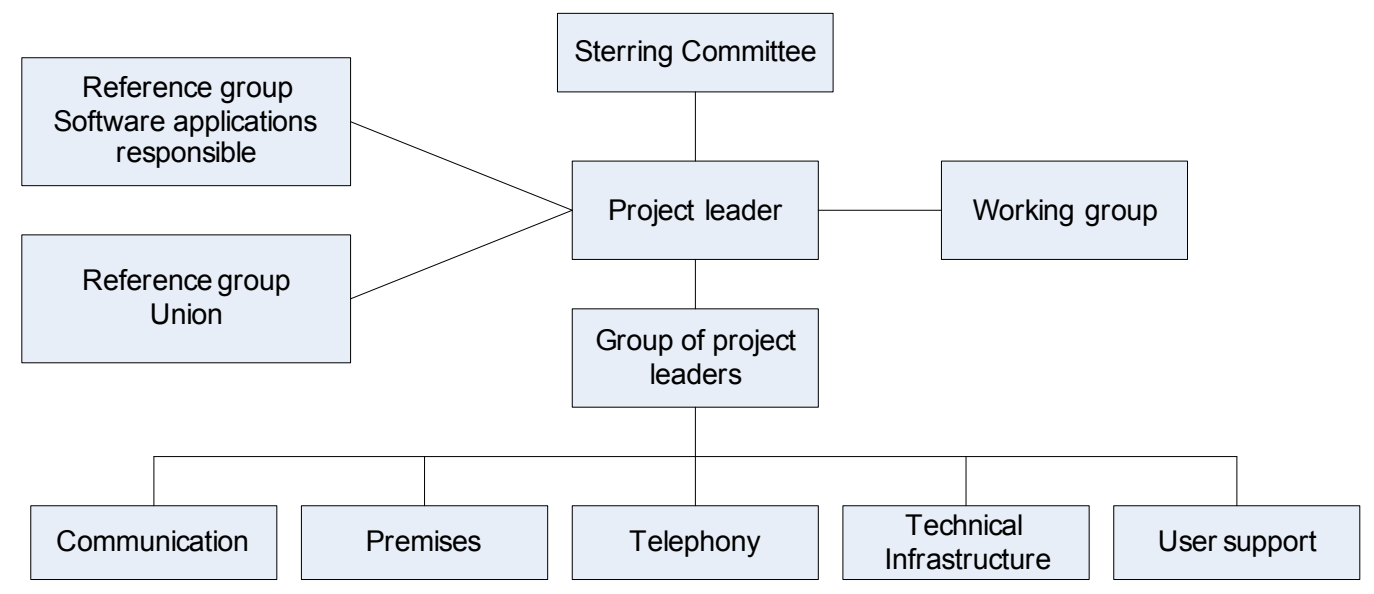

Figure 3. Organisation of Coordinating project at the municipality

The consultancy report was presented in October 2002 and resulted in a decision taken by the municipal executive board, in December 2002, where they gave the commission to the municipal executive office, in cooperation with involved offices, to investigate the possibility to coordinate hosting of software applications to the planned data centre. The next step in this decision-making process and the step that probably had most impact on the decision's outcome as well as the commitment of the decision was the employment of the new chief information officer (CIO).

\subsection{The Coordinating Project}

The coordinating project was initiated and started by the CIO almost directly after his employment. The 
CIO started to work in 2003 and immediately organised the decision-making process as a project. He organised the project into five sub-projects: communication, premises, telephony, technical infrastructure and user support (Figure 3). The organisation of the involved in the project were, a steering committee, a reference group consisting of employees with responsibility for software applications, a reference group with representatives from the union, a group of project leaders from the sub-projects and a working group directly connected to the project leader. The main work was done in the group of project leaders and the working group.
The municipality had, during the time from the decision in the municipality executive board to the time when the CIO was in place, not been able to work with the directives given. The CIO state during the interview "I found almost immediately that the decision taken had low commitment in the organisation and that it would not be possible to implement the decision with that low commitment" This is probably one of the reason for the start of the project. However, to initiate the project the CIO organised a workshop that lasted for two days. During that workshop the project plan shown in Figure 4 was created and agreed upon.

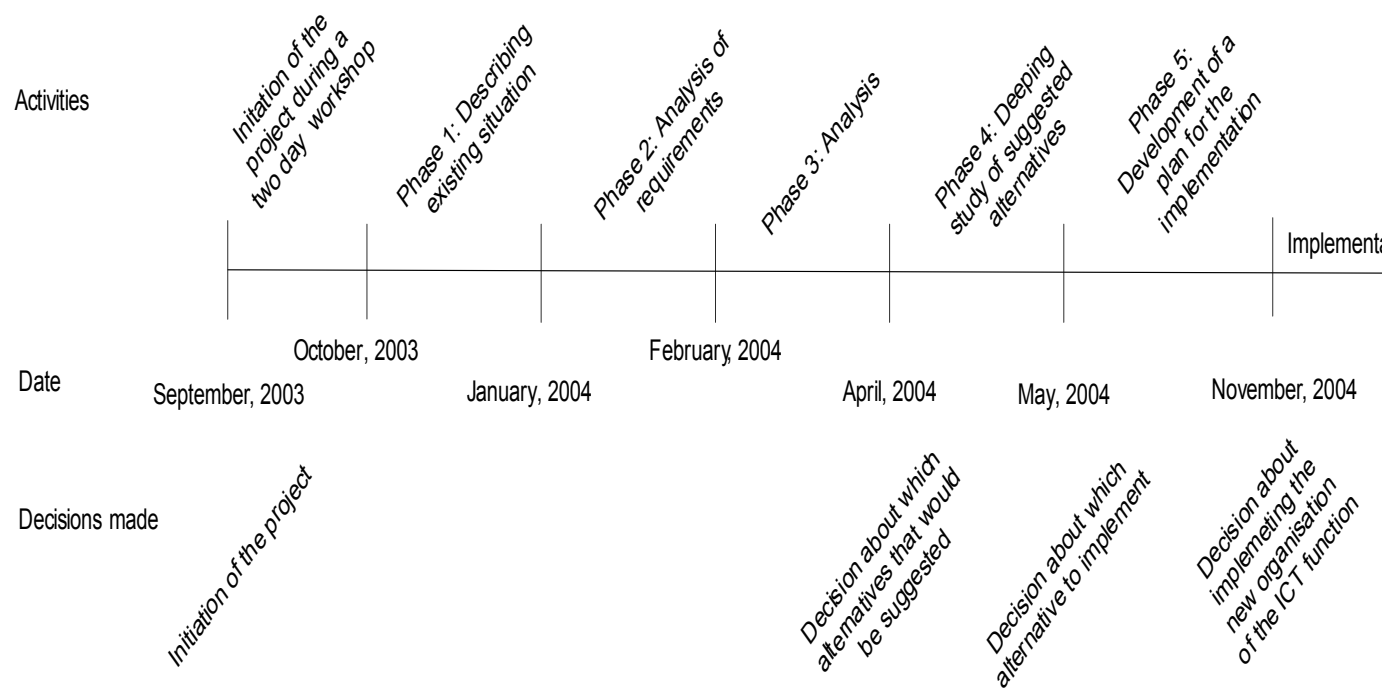

Figure 4. Project plan over the coordination plan

At the workshop the directive from the municipality's executive board was discussed. The workshop resulted in a project plan but also in statements about purpose and goal of the project. In the project plan, this is described in the following way: "The purpose is to investigate, within the frame of coordinated ICT and telephony, the possibility to coordinate hosting of ICT including the major part of hosting of software applications used at different offices" and "The goal is to develop a well anchored foundation for the decision in the municipality's executive board". The five phases are described as follows:

Phase 1: Describing the present situation. The aim of this phase was to develop a collective description of all the offices work tasks regarding ICT and telephony. The description should include the following areas: services, software applications and technical infrastructure, governance and management, coordination with others, roles and responsibilities, organisation, competences and man power, economical resources and culture. The description should also describe which software applications that are developed internal and which are bought. An important part of the description was to clearly describe the offices' view of what development, maintenance and hosting are and categorise the work done into those three categories.
Phase 2: Analysis of requirements. This analysis aims at making a map over present as well as future demands and needs the offices have of software applications. The demands and needs were supposed to be described in functional as well as economical terms. Demand of functionality could be described as, for instance, availability, security, support, capacity, and so on. In addition to this, also demand and need from the different offices of common software for the entire municipality, between different offices as well as the need of software applications in the cooperation with external partners should be described.

Phase 3: Analysis. During this phase demands in the form of restrictions that directly or indirectly affect hosting of software applications should be identified. This could be described as restrictions on the budget or policies and so on. This phase should use results from phase one and phase two as well as the restrictions identified in this phase and from that develop different alternatives. The alternatives should be described, analysed, evaluated, calculated and prioritised. This phase should result in a decision of which alternative that should be suggested.

Phase 4: A further study of the suggested alternative. This alternative should be investigated in more depth and be combined with a plan for the 
implementation as well as a budget. This phase should result in a description of the implemented alternative.

Phase 5: The development of a plan for the implementation. From the decision taken by the municipal executive board a three-year activity plan with budget attached should be developed. The activity plan should discuss both daily activities as well as the evolution that are demanded for having an effective hosting in the future. Necessary investments should also be described in the plan.

The CIO then presented a report to the municipal executive board, in October 2004, in which the result of the project was described. He stated in that report that the decision is necessary to position the municipality for its future development. He described the decision as choosing between two different options. The options were to "continue with the ICT infrastructure that historically has been built up at the different offices with a very low grade of coordination" or "to coordinate the ICT function and telephony for better usage of existing resources making the municipality prepared to meet future challenges and possibilities to increased effectiveness".

The basic data for the decision-making was a report from the project work, a register over investments necessary from 2005 to 2007 and a compilation of costs for the hosting of software applications after the reorganisation. The municipal executive board decided on the option aimed at restructuring and coordinating hosting of software applications in the municipality. Since this decision demands going beyond the decided budget, it needed to be decided upon in the municipal council. This was granted in November 2004, and the decision was to coordinate the hosting of software applications in the planned new data centre. The decision by the municipal council was unanimous.

\section{Discussion}

The case described in this paper is a political organisation and according to Brunsson (1985) political organisations have special difficulties in achieving organisational action. The reason is that a political organisation builds on the basic assumption that there should be conflicts, which is a result from the fact that in a political organisation there are several different ideologies. According to Brunsson, political organisations should not be labelled as organisations; rather, it would be better to label them as arenas for conflicts. However, conflicts do not solve problems and the typical political organisation needs to solve problems. To solve problems in political organisation,s they need to have an integrative or organising force. The solving solution for this problem is to have a rationalistic behaviour. But, as Brunsson states, a rationalistic behaviour is not the best solution for having rational action. For a political organisation it is important to separate politics from actions. This means that it most often is the administrative organisation that suggests the action which then is defended by the political organisation. The case shows that it was mainly one office in the administrative units that started the process. This resulted in low commitment among other offices. The commitment among the politicians was high but it was found that the decision would probably receive problems in the implementation. To solve this problem, the CIO started what could be described as an irrational decision-making process. The findings show that politicians are heavily dependent on the experts in the organisation. The municipality case shows that the decision-making process was influenced to a great extent by a specific decision-maker, in this case the CIO. It also shows how the CIO governed the decision process so that the administrative units felt they had the freedom to make suggestions and decisions. At the same time as the commitment for the change in the organisation increased.

Uncertainty plays an important role in the decision-making and if the process becomes a rational process or an irrational process. However, according to Brunsson, rationality comes in two different settings when discussing decision-making: decisions rationality and action rationality. This can be connected to the discussion about bounded rationality by Simon (1976). Simon claims that bounded rationality of decision-making is present when the decision-makers do not have enough information or the right information to be able to choose and decide in a whole rational manner. Uncertainty has also, as described by Hatch (1997), a close connection to the amount of information. During the interviews it was found among especial the steering committee that they found it hard to judge if the project was on the right track or not since it was so much information to be acquainted with. On the other side, they asked for more information about different alternatives. This was not fulfilled and the interpretation is that the CIO had the opinion that if there had been more information about different alternatives this had probably increased the uncertainty instead of decreasing it. This can be described as information overload as well as a need for new or more information at the same time.

The conclusion possible to make from the discussion by Brunsson is that it is fruitful to distinguish between decision rationality and action rationality when describing a decision-making process. It can be stated that decisions that are described as irrational probably are rational from an organisational action point of view. Irrational decision-making and organisational action are probably to a great extent influenced by each other. It can be concluded that if the decision-making process is seen as rational that will more likely increase commitment on the process. However, the irrational decision-making process will more likely increase commitment for the decision from the process. It could be asked if it is possible to increase commitment on the process as well as on the outcome of the decision at the same time. The municipality case describes one way of doing that. The CIO of the municipality found that the commitment of the 
directive taken in 2002 was low. He therefore started a sourcing decision process that was seen as at least from the outside as a rational decision-making process. By doing so he increased the commitment of getting involved in the process and when the involvement increased it was easier to conduct what could be seen as an irrational decision-making process aiming at increasing commitment of the outcome of the decision.

One weakness of this research is that it has not followed the process in parallel. However, to handle that it has used the possibility of openness in the municipality, which means that there is a lot of documentation that have been studied and related to the interviews. By having the possibility to do so the weakness of not following the process has been possible to handle. However, this indicates another weakness that often is discussed when it comes to political organisations: it is not possible to compare a decisionmaking process in a political organisation with a decision-making process in a non-political organisation. But in this case it is possible to compare since the decision process has been done from a directive that was open for interpretation of what to do. The politicians had no directive of how it should be done, and decisions taken by the politicians in the process could certainly be compared to decisions that an executive board would take in a non-political organisation.

\section{Conclusions}

Evolution of software applications has made that organisations have to change from being a changeable organisation to becoming more of a changeful organisation. This is especially important for political organisations such as the municipality described in this paper. To do that, it has to conduct its decision processes in a way that organisational action happens. One way of doing that is to conduct a sourcing decision process as an irrational decision-making process. The sourcing decision process started as a rationalistic process. However, this was found not to be a successful way. The process therefore adopted an impressionistic method for the sourcing decision. This meant that the process took longer time than it would have done otherwise. It also meant that the process focused a lot of the present situation and evaluated an already decided alternative from the present situation in the municipality. The main reason for doing this was the low motivation and the low commitment of the suggested alternative at the start of the sourcing decision process.

Despite the fact that there were weak motivation for doing this reorganisation at the start of the decision-making process and thereby low commitment among involved stakeholders, the process ended up with high commitment for doing the reorganisation. The sourcing decision could be described as a decision-making paradox since the outcomes were already decided on at the start of the decision process. But, the goal of this process had not been possible to fulfil without conducting the process. The outcome and the possibility to implement the outcome is very much an effect of how the decision-making process was conducted and in that way a result of the high involvement among stakeholders that are supposed to be affected by the decision.

\section{References}

[1] N. Brunsson. The Irrational Organization: Irrationality as a Basis for Organizational Action and Change. Chichester: John Wiley \& Sons Ltd., 1985.

[2] E. Brynjolfsson. The Productivity Paradox of Information Technology: Review and Assessment. Working paper, MIT Sloan School of management, 1992. http://ccs.mit.edu/papers/CCSWP130/CCSWP130.htm l 2005-05-18.

[3] E. Brynjolfsson. The IT Productivity Gap. Optimize, Vol.21, 2003, 1-6. http://www.optimizemag.com 200504-19.

[4] N.G. Carr. IT Doesn't Matter. Harvard Business Review, May 2003 edition.

[5] N.G. Carr. Does IT matter? : Information Technology and the Corrosion of Competitive Advantage. Boston, Mass.: Harvard Business School Press, 2004.

[6] J. Dibbern, T. Goles, R. Hirschheim, B. Jayatilaka. Information Systems Outsourcing: A Survey and Analysis of the Literature. The DATA BASE for Advances in Information Systems - Fall 2004, Vol.35, No.4, 6 - 102.

[7] L. Eriksen. Will the Real Utility Computing Model Please Stand Up, 2003. http://www.UtilityComputing. com/news/342.asp 2005-05-12.

[8] T. Falk. Den nya ekonomin: Teknikskifte och en ny affärslogik. Svenskt Näringsliv, Confederation of Swedish Enterprise, 2003. http://sn.svensktnaringsliv. se/SN/Publi.nsf/.

[9] N. Gorla, E. Chan, P. Oswald. Determinations of IS Outsourcing Decision: Development of an Integrated Model and Test. In the proceedings of the Eighth American Conference on Informations Systems, 2002, $2274-2285$.

[10] G.A. Gorry, M.S. Morton. A Framework for Management Systems. MIT Sloan Management Review. Vol.30, No.3, 1989, 49 - 61.

[11] M.J. Hatch. Organization Theory Modern, Symbolic, and Postmodern Perspectives. Oxford University Press Inc., New York, 1997, 1 - 20.

[12] S. Junghagen. Strategiska förhållningssätt till informationsteknik i små företag. Umeå: Umeå Universitets tryckeri, 1998.

[13] J. Jurison. The role of risk and return in information technology outsourcing decisions. Journal of Information Technology, 10, 1995, 239 - 247.

[14] F.J.Mata, W.L. Fuerst, J.B. Barney. Information Technology and Sustained Competitive Advantage: A Resource-Based Analysis. MIS Quarterly, December, Vol.19, No.4, 1995, 487 - 505.

[15] D. McCauley. Reaping the benefits of ICT, Europe's productivity challenge. A report from the Economist Intelligence Unit sponsored by Microsoft, 2004. http://graphics.eiu.com/files/ad_pdfs/MICROSOFT_FI NAL.pdf (20041028). 
[16] S.J. Miller, D.J. Hickson, D.C. Wilson. DecisionMaking in Organizations. In Salamans (eds.). Decision Making for Business, A Reader. SAGE Publications Ltd., 2002, 74 - 95.

[17] A.M. Pettigrew. The Politics of Organizational Decision-making. London: Tavistock Publications Limited, 1973.

[18] G. Salaman. Introduction. In Salamans (eds.). Decision Making for Business, A Reader. SAGE Publications Ltd., 2002, 1 - 5 .

[19] H.A. Simon. Administrative Behavior: A Study of Decision-Making Processes in Administrative Organization. 3ed. New York: Free Press, 1976.

[20] H. Smith, P. Fingar. IT doesn't matter - business processes do : a critical analysis of Nicholas Carr's I.T. article in the Harvard Business Review. Tampa, Fla: Meghan-Kiffer, 2003.
[21] G.G. Udo. Using analytic hierarchy process to analyze the information technology outsourcing decision. Industrial Management \& Data Systems. MCB University press 100/9, 2000, $421-429$. http://www.emerald-library.com.

[22] W. Van Grembergen, S. De Haes, E. Guldentops. Structures, Processes and Relational Mechanisms for IT Governance. In (ed.), Van Grembergen, W. Strategies for Information Technology Governance. Hershey, PA: Idea Group Publishing, 2004.

[23] L. Willcocks, S. Lester. Beyond the IT Productivity Paradox. European Management Journal, 14(3), 1996, $279-290$

[24] O.E. Williamson. Market and Hierarchies: Analysis and Antitrust Implications, a study in the economics of internal organization. Free Press, New York, 1975.

Received August 2006. 